\title{
EDUCAÇÃO AMBIENTAL: LEVANTAMENTO DAS PRÁTICAS SUSTENTÁVEIS APLICADAS AO SETOR PESQUEIRO (PESCA E AQUICULTURA) COMO FERRAMENTA DE REFLEXÃO
}

Environmental Educacion: Survey of sustainable practices applied to the fisheries sector (fisheries and aquaculture) as a reflection tool

Educación Ambiental: investigación sobre prácticas sostenibles al sector pesqueiro (pesca y acuicultura) como herramienta de reflexión

Thatiane Brito da Silva Medeiros ${ }^{1 *}$, Vinicius Gabriel da Silva Santana ${ }^{1}$, Raimunda Adlany Dias da Silva ${ }^{1}$, Daniele Bezerra dos Santos ${ }^{2}$, Cibele Soares Pontes ${ }^{3 .}$

${ }^{1}$ Programa Regional de Pós-Graduação em Desenvolvimento e Meio Ambiente - PRODEMA, Universidade Federal do Rio Grande do Norte, Natal, Brasil.

${ }^{2}$ Coordenação de Pesquisa e Inovação - COPEIN/DG/PF/RE, Instituto Federal de Educação, Ciência e Tecnologia do Rio Grande do Norte, Pau dos Ferros, Brasil.

${ }^{3}$ Unidade Especializada em Ciências Agrárias-EAJ, Universidade Federal do Rio Grande do Norte, Macaíba, Brasil.

*Correspondência: e-mail: thatybrito.rn@bol.com.br.

\section{Artigo recebido em 17/04/2020 aprovado em 03/11/2020 publicado em 05/03/2021}

\section{RESUMO}

Diante do agravamento da crise ambiental global é indispensável um esforço para a educação em questões ambientais, na finalidade de fundamentar a conduta dos indivíduos, das empresas e das coletividades inspirada no sentido de sua responsabilização sobre a proteção e conservação do meio ambiente. O estudo teve por intuito realizar um levantamento das práticas sustentáveis aplicadas aos segmentos da atividade pesqueira, bem como analisar alternativas que favoreçam o desenvolvimento sustentável do setor, apresentando sugestões descritas na literatura, para os problemas que afetam a atividade, integrando benefícios ecológicos, econômicos e sociais. Para a realização deste estudo foi realizada a seguinte pergunta investigativa "Quais estudos da literatura apresentam práticas sustentáveis na área de recursos pesqueiros (pesca e aquicultura)?”. Assim, a escolha pelo levantamento bibliográfico ocorreu pela adequação da metodologia de estudo ao objetivo da pesquisa. Para este levantamento identificou-se que a maioria das práticas ambientais implementadas ou ações sugeridas se relacionou com pesquisas científicas ligadas à indústria, instituições, ou aspectos etnológicos e poucos estudos estiveram relacionadas à área educacional disciplinar. Considerou-se que os estudos acerca das práticas de sustentabilidade direcionadas ao setor pesqueiro são incipientes, com produção muito exígua quando comparados com a mesma temática para outras áreas.

Palavras-chave: Pesca, Aquicultura, Sustentabilidade ambiental.

\section{ABSTRACT}

In view of the worsening of the global environmental crisis, an effort for education on environmental issues is essential, with the objective of supporting the conduct of the individuals, companies and collective activities inspired in the sense of their responsibility for the protection and conservation of the environment. . The study aimed to carry out a survey of the sustainable practices applied to the segments of fishing activity, as well as to analyze alternatives that favor or develop the sustainable development of the sector, presenting suggestions described in the literature, for the problems that affect the activity, integrating ecological, economic and social benefits. To carry out this study, the following investigative question was asked "Which literature studies have sustainable practices in the area of fisheries resources (fishing and aquaculture)?" Thus, a choice for the bibliographic survey occurred due to the 
adequacy of the study method to the research objective. For this survey, it is identified that most of the environmental practices implemented or suggested actions are related with the scientific research applied to industries, institutions, ethnological aspects and few studies related with the educational area. Studies on sustainability practices aimed at the fishing sector are considered incipient, with very small production when compared to the same theme for other areas.

Keywords: Fishing; Aquaculture, Environmental sustainability.

\section{RESUMEN}

Ante el empeoramiento de la crisis medioambiental global, es esencial un esfuerzo de educación sobre temas medioambientales, a fin de basar la conducta de las personas, las empresas y las comunidades inspiradas en su responsabilidad de proteger y conservar el medioambiente. El estudio tuvo como objetivo realizar una encuesta de las prácticas sostenibles aplicadas a los segmentos de la actividad pesquera, así como analizar alternativas que favorezcan el desarrollo sostenible del sector, presentando sugerencias descritas en la literatura, para los problemas que afectan la actividad, integrando beneficios ecológicos, económicos y sociales. Para llevar a cabo este estudio, se hizo la siguiente pregunta de investigación "¿Qué estudios en la literatura presentan prácticas sostenibles en el área de los recursos pesqueros (pesca y acuicultura)?". Por lo tanto, la elección de la encuesta bibliográfica se produjo debido a la adecuación de la metodología del estudio al objetivo de la investigación. Para esta encuesta, se identificó que la mayoría de las prácticas ambientales implementadas o acciones sugeridas estaban relacionadas con la investigación científica relacionada con la industria, las instituciones o los aspectos etnológicos y pocos estudios estaban relacionados con el área educativa disciplinaria. Los estudios sobre prácticas de sostenibilidad dirigidos al sector pesquero se consideraron incipientes, con una producción muy pequeña en comparación con el mismo tema para otras áreas.

Descriptores: Pesca, Acuicultura, Sostenibilidad ambiental.

\section{INTRODUÇÃO}

A adição da característica Ambiental ao termo Educação ocorreu diante o agravamento da crise ambiental global na segunda metade do século XX. Em 1972, a Declaração de Estocolmo estabeleceu ser indispensável um esforço para a educação em questões ambientais dirigida tanto às gerações jovens como aos adultos, com o objetivo de fundamentar a conduta dos indivíduos, das empresas e das coletividades inspirada no sentido de sua responsabilização sobre a proteção e melhoria do meio ambiente (ONU, 1972). Após três anos, a Carta de Belgrado reiterou que a Educação Ambiental é um dos elementos fundamentais para a investida geral contra a crise ambiental e tem como objetivo a conscientização de todos os indivíduos, em escala global, em preocupação com o meio ambiente e seus problemas (UNESCO, 1975).

Posteriormente, o relatório intitulado "Nosso futuro comum" criticou o modelo de produção adotado pelos países considerados desenvolvidos, enfatizando os riscos do uso exacerbado dos recursos naturais sem considerar a capacidade de suporte dos ecossistemas, e apresentou o conceito mais amplamente aceito e difundido de Desenvolvimento Sustentável que requer o atendimento das necessidades atuais sem comprometer as das gerações futuras (Comissão Mundial Sobre Meio Ambiente e Desenvolvimento, 1988). Esse conceito se relaciona com a crítica ambientalista ao modo de vida contemporâneo que tem como pressuposto a existência das sustentabilidades social, econômica e ecológica, necessárias à harmonização dos processos socioeconômicos e ambientais, otimizando a extração de matéria-prima e uso de serviços ecossistêmicos (JACOBI, 1997; JACOBI, 2003). O conceito surgiu como enfrentamento da crise ecológica, processo que foi sustentado pelo trabalho do Clube de Roma, visando alcançar a estabilidade econômica e ecológica, 
propondo o congelamento do crescimento da população global e do capital industrial, indicando um viés para o controle demográfico e dos recursos limitados (MEADOWS et al., 1972).

A expressão "sustentabilidade" surgiu após o termo desenvolvimento sustentável e foi amplamente disseminada na sociedade, amparada pelo mesmo conceito normativo do termo. A definição de sustentabilidade tem sido alvo de discussões nos vários encontros mundiais. De acordo com Boff (2017), a expressão "sustentabilidade" deve ser entendida para além da visão antropocêntrica do desenvolvimento sustentável apresentado no relatório de Brundtland. O autor aponta que a expressão é abrangente, abarca além de todos os processos e atividades destinadas à manutenção da vitalidade e integridade da Mãe Terra, também a preservação dos seus ecossistemas com todos os elementos que garantam a existência e reprodução da vida, com possibilidade de atender às gerações presentes e futuras, assim como a conservação, no desenvolvimento e realização das potencialidades humanas em suas diversas expressões (BOFF, 2017).

No que diz respeito à sustentabilidade ambiental, essa está relacionada com as práticas ambientais e tem como propósito principal contribuir para a manutenção e disponibilidade dos recursos naturais, no manejo e tratamento devido dos resíduos produzidos, mitigação dos impactos gerados ao ambiente e a orientação e cumprimento da legislação ambiental (SEVERO e GUIMARÃES, 2017). Para Jacobi (2003), o termo implica na conservação da premissa de que é preciso definir limites às possibilidades de crescimento e delinear um conjunto de iniciativas (práticas) que levem em conta a existência de interlocutores e sujeitos sociais (relevantes e ativos) por meio de práticas educativas e de um processo de diálogo informado, o que reforça um sentimento de corresponsabilidade e de constituição de valores éticos.

Nessa perspectiva, a Educação Ambiental se configura como uma abordagem capaz de permitir a compreensão e, posteriormente, a instrumentalização dos atores sociais para intervenção da realidade socioambiental. Esse processo ocorre em cada indivíduo em sua relação com o coletivo durante o exercício da cidadania. Portanto, a Educação Ambiental em sua visão Crítica objetiva promover ambientes educativos de mobilização desse processo, unindo a ação pedagógica ao movimento social de enfrentamento da crise socioambiental e possibilitando a articulação entre diferentes saberes (GUIMARÃES, 2004).

Os diversos conflitos socioambientais do setor pesqueiro se configuram um campo oportuno de reflexão e intervenção pela Educação Ambiental. A pesca, atividade baseada na extração dos recursos pesqueiros do seu ambiente natural, possui significativa importância quando analisada pela ótica do crescimento da população mundial e sua demanda de consumo desses recursos (FAO, 2018). Porém, a pesca industrial, voltada ao abastecimento dos grandes centros de distribuição com a matéria-prima extraída do ambiente marinho, tem se tornado a principal responsável pela sobre-exploração dos estoques pesqueiros em meio a carência de fiscalização no setor (REBOUÇAS et al., 2006; NASCIMENTO et al., 2015). A atividade pesqueira, segundo a FAO Organização das Nações Unidas para Alimentação e Agricultura, possui índices produtivos estagnados nas últimas décadas enquanto a aquicultura, ramo da produção controlada ou semi-controlada de cultivo de organismos aquáticos, possui índices produtivos em constante crescimento no mundo todo (SIQUEIRA, 2017; FAO, 2018).

Os impactos ambientais decorrentes destas atividades, seja aquicultura ou pesca, podem variar, 
desde escapes acidentais de animais dos viveiros de produção à capturas acidentais de outras espécies de peixes e invertebrados, tendo em vista que algumas artes de pesca geralmente não são capazes de capturar apenas as espécies-alvo desejadas. Essas práticas podem também induzir a diversos impactos ambientais negativos como, por exemplo, a mortalidade acidental de espécies de aves, tartarugas e mamíferos marinhos ou causar danos aos ecossistemas marinhos mais vulneráveis, como os corais (SMITH, 2011; FAO, 2018; FARIAS et al., 2019). Além disto, outros problemas podem ser apontados, tais como, a poluição gerada em alto mar pelas embarcações pesqueiras (GRANZIERA e GONÇALVES, 2012; CHANTHAMALEE et al., 2013) a exemplo dos derramamentos de óleos e das emissões de gases, contribuintes ao agravamento do efeito estufa, e objetos que são abandonados à deriva (MACFADYEN, 2009).

Diante das dificuldades enfrentadas pelo setor pesqueiro, o presente estudo objetivou o levantamento bibliográfico sobre práticas sustentáveis em suas atividades, bem como analisar alternativas que favoreçam seu desenvolvimento sustentável, refletindo sobre sugestões apresentadas na literatura que integrem benefícios ecológicos, econômicos e sociais, com finalidade de dar suporte à mudança de atitude e em consequência nas práticas de educação ambiental.

\section{MATERIAIS E MÉTODOS}

Para a realização deste estudo formulou-se a seguinte pergunta investigativa "Quais estudos da literatura apresentam práticas sustentáveis na área de recursos pesqueiros (pesca e aquicultura)?". Deste modo, a escolha pelo levantamento de dados bibliográficos ocorreu pela adequação da metodologia de estudo ao objetivo da pesquisa.
A presente pesquisa possui caráter qualitativo, é classificada como exploratória, descritiva. Esta constituída, por meio de um levantamento bibliográfico sobre as principais práticas sustentáveis aplicadas ao setor pesqueiro (pesca e aquicultura). $\mathrm{O}$ levantamento de dados realizado seguiu um processo de quatro etapas: $1^{\mathrm{a}}$ construção de pergunta científica para guiar o levantamento; $2^{\mathrm{a}}$ definição de protocolo de pesquisa (base de dados e termos de busca); $3^{\text {a }}$ seleção dos artigos com base em um conjunto predeterminado de critérios e $4^{\mathrm{a}}$ análise e síntese da literatura selecionada, todas já testadas em estudos anteriores (PLUMMER et al., 2012; MOORE et al., 2014; PITTMAN e ARMITAGE, 2016).

Para isso, realizou-se um apuração dos trabalhos disponíveis e publicados no período compreendido entre 2008 e 2019 com seleção de artigos de caráter científico-acadêmico, publicados em língua inglesa e portuguesa. Com uso das bases de dados eletrônicas: Periódicos da Coordenação de Aperfeiçoamento de Pessoal de Nível Superior (CAPES), Scientific Eletronic Library Online (SciELO) e Red de Revistas Científicas de América Latina y el Caribe, España y Portugal (Redalyc). E os seguintes termos-chave: "práticas sustentáveis + pesca"; "sustentabilidade + aquicultura"; "práticas sustentáveis + recursos pesqueiros" e seus correspondentes em inglês: "sustainable practices + fishing"; "sustainability + aquaculture"; "sustainable practices + fishing resources".

Para critérios de seleção, após o levantamento dos trabalhos científicos, foram selecionadas os que trataram e discutiram enfaticamente as palavras-chave, relacionadas à temática e analisados de acordo com os seguintes critérios: 1) trabalhos publicados e disponíveis integramente para consulta; 2) trabalhos publicados entre os anos de 2008 a 2019; 3) trabalhos em que o título do trabalho ou resumo enquadrava-se ou se relacionavam com a temática da pesquisa; 4) 
trabalhos relacionados com as ciências ambientais e áreas afins. Para critérios de exclusão, foram descartados trabalhos duplicados, trabalhos que não tratavam sobre a temática (recursos pesqueiros) e os que não se relacionavam a área das ciências ambientais e afins. Posteriormente os artigos foram analisados e categorizados.

\section{RESULTADOS E DISCUSSÃO}

Para a primeira fase da pesquisa, busca empregando os termos "Práticas Sustentáveis + Pesca", "Práticas Sustentáveis + Aquicultura" e "Práticas Sustentáveis + Recursos Pesqueiros", em que foram analisadas as literaturas de livre acesso que se encontraram disponíveis na íntegra, nas áreas das ciências ambientais e áreas afins, nas três bases adotadas. Fui observado que a base Redalyc retornou 439 publicações para os termos em português e 136 para os termos em inglês; já a base CAPES retornou 49 publicações para os termos em português, porém não houve análise para os termos em inglês nesta base em virtude do grande número de artigos e a dificuldade na utilização dos critérios; já na base de dados SciELO foi verificado o retorno de apenas 05 artigos com temos em português e 06 para os termos em inglês, Todos publicações filtrados somaram um total de 635 artigos. Na segunda fase da pesquisa, foram verificados que um total de 623 literaturas não estavam de acordo com os critérios da pesquisa sendo, portanto, rejeitados bem como as literaturas duplicadas.

Desta forma foram identificadas as 12 literaturas mais relevantes na abordagem da temática e que atenderam aos critérios de inclusão deste levantamento, resultando em cinco artigos na base Redalyc para os termos em português e três para os termos em inglês; um artigo na base CAPES e três artigos na base SciELO para os termos em português e um para os termos em inglês; todos na integra apresentando texto completo disponível e para consulta online.
A apresentação dos estudos selecionados através do levantamento bibliográfico, estão expostos no quadro 1 . Os estudos selecionados tiveram os anos de publicações a partir de 2008, e indicou aumento na produção dos trabalhos na área da temática para os anos de 2010, 2014, 2018 e 2019. Para a língua original de publicação 07 (sete) foram publicados em português e 05 (cinco) na língua inglesa, sendo que para o Brasil, nos últimos anos houveram mais publicações da temática na língua materna. No que diz respeito a classificação dos artigos segundo seus respectivos periódicos a maiorias tem classificação Qualis - Capes (2103-2016) B1 para as áreas das Ciências Ambientais no total de 09 periódicos, 01 (um) periódico com classificação B2, 01 para B3 na área de Recursos Pesqueiros e 01 sendo criado a partir de 2013, portanto ainda sem classificação.

Mediante o levantamento bibliográfico, foi possível identificar três principais categorias de 85 trabalho desenvolvidas nos períodos entre 2008 e 2019, sendo a primeira Educação ambiental, segunda Gestão de recursos naturais, e terceira e última Indústria e práticas sustentáveis. Para a categoria Educação ambiental foram identificados 04 estudos relacionados, enquanto que para a categoria Gestão de recursos naturais foram identificados 05 estudos, e para a categoria Industria e práticas sustentáveis foram identificados 03 estudos.

Para detalhamento dos estudos, observou-se que 08 (oito) estudos trataram da temática em áreas interdisciplinares das ciências agrárias e/ou ambientais e 04 (quatro) estudos trataram da temática na área educativa ambiental, sendo para esta área: 01 (um) estudo para o ano 2014, 01 (um) estudo para o ano de 2018, e 02 (dois) estudos para o ano de 2019, dos quais o primeiro está relacionado com a educação formal e não formal, os dois seguintes estão relacionados à educação formal e o último à educação não formal. 
Quadro 1. Estudos que trataram sobre as práticas sustentáveis no setor pesqueiro.

\begin{tabular}{|c|c|c|c|c|c|}
\hline $\mathbf{N}$ & Estudo & Autor & $\begin{array}{l}\text { Local/ } \\
\text { Ano }\end{array}$ & $\begin{array}{ll}\text { Língua original de } \\
\text { publicação }\end{array}$ & Periódico/ Qualis \\
\hline (A) & \begin{tabular}{l}
\multicolumn{2}{l}{ Desenvolvimento } \\
sustentável no litoral \\
semiárido potiguar: o \\
processo r de \\
consolidação \\
reserva \\
desenvolvimento \\
sustentável estadual \\
ponta do tubarão em \\
Macau/RN \\
Guamaré/RN
\end{tabular} & $\begin{array}{l}\text { NÓBREGA, } \\
\text { A. E. de O.; } \\
\text { MUSSE, N. } \\
\text { S. de O. }\end{array}$ & $\begin{array}{l}\text { Brasil, } \\
2019\end{array}$ & Português & $\begin{array}{l}\text { GEOSABERES: } \\
\text { Revista de Estudos } \\
\text { Geoeducacionais/B } \\
3\end{array}$ \\
\hline (B) & $\begin{array}{l}\text { Formação continuada } \\
\text { de professores de } \\
\text { ciências utilizando a } \\
\text { Aquaponia como } \\
\text { ferramenta didática }\end{array}$ & $\begin{array}{l}\text { SOUZA, } \\
\text { R.T. Y. B. de } \\
\text { et al. }\end{array}$ & $\begin{array}{l}\text { Brasil, } \\
2019\end{array}$ & Português & $\begin{array}{ll}\text { Ciência } & \& \\
\text { Educação/B1 }\end{array}$ \\
\hline (C) & $\begin{array}{l}\text { Ações } \\
\text { desenvolvimento } \\
\text { sustentável em Santa } \\
\text { Catarina: foco nas } \\
\text { bibliotecas publicas }\end{array}$ & $\begin{array}{l}\text { PINTO, M. } \\
\text { D. S. et al }\end{array}$ & $\begin{array}{l}\text { Brasil, } \\
2018\end{array}$ & Português & $\begin{array}{l}\text { Informação \& } \\
\text { Sociedade/B1 }\end{array}$ \\
\hline (D) & $\begin{array}{l}\text { Growth And } \\
\text { Development Of } \\
\text { Herbaceous Plants In } \\
\text { Aquaponic Systems }\end{array}$ & $\begin{array}{l}\text { ESPINOSA- } \\
\text { MOYA, A. et } \\
\text { al. }\end{array}$ & $\begin{array}{l}\text { México, } \\
2018\end{array}$ & Ingles & Acta Universitaria/- \\
\hline (E) & $\begin{array}{l}\text { Desafios la } \\
\text { carcinicultura: } \\
\text { aspectos legais, } \\
\text { impactos ambientais e } \\
\text { alternativas } \\
\text { mitigadoras }\end{array}$ & $\begin{array}{l}\text { RIBEIRO, L. } \\
\text { F. et al. }\end{array}$ & $\begin{array}{l}\text { Brasil, } \\
2014\end{array}$ & Português & $\begin{array}{l}\text { Revista de Gestão } \\
\text { Costeira } \\
\text { Integrada/B1 }\end{array}$ \\
\hline (F) & $\begin{array}{l}\text { Mudanças climáticas, } \\
\text { educação e meio } \\
\text { ambiente: para além do }\end{array}$ & $\begin{array}{l}\text { LIMA, G. F. } \\
\text { da C.; } \\
\text { LAYRARG } \\
\text { UES, P. P. }\end{array}$ & $\begin{array}{l}\text { Brasil, } \\
2014\end{array}$ & Português & $\begin{array}{l}\text { Educar } \quad \text { em } \\
\text { Revista/B1 }\end{array}$ \\
\hline
\end{tabular}




\begin{tabular}{|c|c|c|c|c|c|}
\hline & $\begin{array}{l}\text { Conservadorismo } \\
\text { Dinâmico }\end{array}$ & & & & \\
\hline (G) & $\begin{array}{l}\text { Mecanismos } \\
\text { socioecológicos } \\
\text { práticas tradicionais de } \\
\text { pesca na comunidade } \\
\text { caiçara da Ilha Diana } \\
\text { (Santos, Brasil) e suas } \\
\text { transformações }\end{array}$ & $\begin{array}{l}\text { STORI, F.T.; } \\
\text { NORDI, N.; } \\
\text { ABESSA, D. } \\
\text { M. de S. }\end{array}$ & $\begin{array}{l}\text { Brasil, } \\
2012\end{array}$ & Português & $\begin{array}{l}\text { Revista de Gestão } \\
\text { Costeira } \\
\text { Integrada/B1 }\end{array}$ \\
\hline (H) & $\begin{array}{l}\text { Aquaculture and } \\
\text { fisheries crisis within } \\
\text { the global crisis }\end{array}$ & $\begin{array}{l}\text { PERDIKARI } \\
\text { S, C.; } \\
\text { PASCHOS, } \\
\text { I. }\end{array}$ & $\begin{array}{l}\text { Grécia, } \\
2011\end{array}$ & Inglês & Interciencia/B1 \\
\hline (I) & $\begin{array}{l}\text { How are the lakes? } \\
\text { Environmental } \\
\text { perception } \\
\text { fishermen and alien } \\
\text { fish dispersal in } \\
\text { Brazilian tropical lakes }\end{array}$ & $\begin{array}{l}\text { LIMA, F. P.; } \\
\text { LATINI, A. } \\
\text { O.; MARCO } \\
\text { JUNIOR P. } \\
\text { de }\end{array}$ & $\begin{array}{l}\text { Brasil, } \\
2010\end{array}$ & Inglês & Interciencia/B1 \\
\hline (J) & $\begin{array}{l}\text { Artisanal fisheries in } \\
\text { the conservation zones } \\
\text { of the Upper Gulf of } \\
\text { California }\end{array}$ & $\begin{array}{l}\text { QUIROZ, G. } \\
\text { R. et al. }\end{array}$ & $\begin{array}{l}\text { EUA, } \\
2010\end{array}$ & Inglês & $\begin{array}{l}\text { Revista de Biología } \\
\text { Marina y } \\
\text { Oceanografía/B2 }\end{array}$ \\
\hline (L) & $\begin{array}{l}\text { Limnological } \\
\text { evaluation of the } \\
\text { fisheries potentials and } \\
\text { productivity of a small } \\
\text { shallow tropical } \\
\text { African reservoir }\end{array}$ & $\begin{array}{l}\text { MUSTAPH } \\
\text { A, M. K. }\end{array}$ & $\begin{array}{l}\text { Nigéria, } \\
2009\end{array}$ & Inglês & $\begin{array}{l}\text { Revista de biologia } \\
\text { tropical/B1 }\end{array}$ \\
\hline (M) & $\begin{array}{l}\text { O uso dos recursos } \\
\text { pesqueiros no estuário } \\
\text { do Rio Mamanguape, } \\
\text { Estado da Paraíba, } \\
\text { Brasil }\end{array}$ & $\begin{array}{l}\text { ROCHA, } \\
\text { M.S.P.; et al. }\end{array}$ & $\begin{array}{l}\text { Brasil, } \\
2008\end{array}$ & Português & Interciencia/B1 \\
\hline
\end{tabular}

Quanto aos objetivos dos trabalhos selecionados, todos apresentam diferentes interesses. Para os trabalhos relacionados à primeira categoria Educação ambiental, o estudo de Nobrega; Musse
(2019) apresentou o desenvolvimento sustentável no litoral semiárido potiguar por meio do processo de consolidação da Reserva de Desenvolvimento Sustentável Ponta do Tubarão (RDSEPT); o estudo foi 
estruturado a partir da discussão dos conceitos de Desenvolvimento sustentável e Educação Ambiental, no qual também foram propostas a apresentação das principais atividades econômicas desenvolvidas na reserva e as medidas utilizadas na comunidade local para promover a sensibilização e a conscientização ambiental. O estudo de Souza et al. (2019) trabalhou no desenvolvimento da formação de professores de ensino médio em disciplinas como química, física, biologia e matemática; procurando compreender como a utilização de um sistema integrado de aquaponia pode servir como suporte para realização de atividades pedagógicas, com foco no desenvolvimento da ciência. O estudo trouxe como objeto de análise o potencial pedagógico do sistema e seus impactos na prática docente. Já o estudo de Pinto et al. (2018) buscou analisar as ações que são desenvolvidas nas Bibliotecas Públicas Catarinenses e que estão de acordo com a Agenda 2030, o foco girou em torno da sustentabilidade. No estudo de Lima; Layrargues (2014) foi discutido a complexidade da crise climática, as possíveis contribuições da educação ambiental para o seu equacionamento e as principais respostas presentes e ausentes do debate sobre o tema.

Para os trabalhos relacionados à segunda categoria Gestão de recursos naturais, o estudo de Rocha et al. (2008) inventariou os usos dos principais recursos pesqueiros procedentes do estuário do rio Mamanguape, localizado no Estado da Paraíba, Brasil, estabelecendo sua utilização e importância para reprodução social e para corroborar no desenvolvimento de planos de manejo e uso sustentável da comunidade residente. Já o estudo de Lima; Latini; Marco Junior (2010) avaliou a percepção ambiental de comunidades locais quanto à dispersão intencional de peixes em lagos na bacia do rio Doce, sudoeste do Brasil e suas consequências para as populações de peixes nativos. O estudo de Quiroz et al. (2010) identificou e computou o estado das pescarias artesanais e seu valor econômico no Alto Golfo da Califórnia como uma estratégia para implementação de um plano de conservação no intuito de reduzir a atividade pesqueira artesanal em áreas marinhas protegidas. O estudo de Perdikaris; Paschos (2011) buscou examinar a complexidade da crise do setor da aquicultura e pesca dentro de um contexto amplo da crise global. Enquanto que o estudo de Stori; Nordi; Abessa (2012) identificou os aspectos relacionados à cultura caiçara que estão presentes na comunidade da Ilha Diana e das suas práticas tradicionais de manejo, baseadas no conhecimento tradicional sobre a pesca, e mecanismos sociais relacionados e analisou as transformações e adaptações deste modo de vida e território ao longo do tempo.

Para os estudos que se enquadram na Terceira categoria Indústria e práticas sustentáveis, tem-se para os trabalhos no Brasil, em especial os trabalhos não 88 relacionados à educação, o estudo de Ribeiro et al. (2014) que teve como finalidade fazer uma revisão sobre a atividade de carcinicultura brasileira envolvendo os aspectos legais que controlam esta atividade, bem como intencionou relatar os principais impactos ambientais advindos da aquicultura, em especial da atividade da carcinicultura (cultivo de crustáceos) e as ações mitigadoras atualmente utilizadas no Brasil. Para os estudos não relacionados à educação e fora do Brasil, o trabalho de EspinosaMoyaet al. (2018), procurou avaliar o crescimento e desenvolvimento de espécies como o mangericão (Ocimum basilicum L.), hortelã-pimenta (Mentha piperita L.) e hortelã (Mentha spicata L.), em ambiente de aquaponia com tilápia (Oreocrhomes niloticus), como parte de um filtro biológico. Já o trabalho de Mustapha (2009) buscou determinar a produção potencial de peixes do reservatório artificial de Oyum, em Offa estado de Kwara na Nigéria. 
Quanto aos instrumentos metodológicos de coleta de dados, o estudo (A) se utilizou da Pesquisa bibliográfica e do estudo de campo, por meio do qual o reconhecimento da localidade foi feito e os registros fotográficos foram produzidos. O estudo (B) se utilizou da pesquisa bibliográfica, entrevista e diálogo com professores de uma escola estadual de nível médio, no município de Itacoatiara, AM. O estudo (C) se utilizou da pesquisa bibliográfica, descritiva e exploratória e um questionário composto por 25 questões relacionadas às bibliotecas. $\mathrm{O}$ estudo (D) utilizou-se de um macro túnel com filme e tela de plástico para a proteção dos sistemas aquapônicos, além de três sistemas aquapônicos iguais, cada um constituído por uma lagoa circular, um clarificador e três biofitadores. O estudo (E) utilizou a pesquisa bibliográfica, consultando a legislação e resoluções para o setor aquícola. Os estudos (F) e (H) aplicaram a pesquisa bibliográfica, exploratória e analítica para cumprir os propósitos dos estudos. O estudo (G) utilizou a pesquisa bibliográfica e qualitativa, além de uma abordagem etnoecológica entrevistando 20 pessoas da comunidade estudada. Os estudos (I) e (J) aplicaram a pesquisa bibliográfica e entrevistas a participantes das pesquisas utilizando-se também de um questionário. O estudo (L) utilizou a morfometria e parâmetros físico-químicos para estimar o potencial de produção de peixes. O estudo (M) utilizou a pesquisa bibliográfica, qualitativa (com entrevistas e observação direta com 30 pessoas) e abordagem quantitativa.

\section{Práticas sustentáveis e sugestões de ações ambientais}

Entre os principais resultados observados em cada estudo, que se relacionam com as práticas e ações ambientalmente sustentáveis tem-se para a primeira categoria Educação ambiental, um estudo relacionado a sistemas aquapônicos em território brasileiro para o ano de 2019, no estudo (B), indicando que a utilização de sistemas aquapônicos como prática sustentável de mitigação para o setor, vem surgindo nos últimos anos. Para o estudo (B) o sistema aquapônico é apresentado como um projeto de caráter sustentável e de baixo custo com grande potencial para ferramenta auxiliar da práxis pedagógica extraclasse. É preciso levar em conta que o trabalho do autor foi realizado com alunos e professores do ensino médio, mas que não impede de ser trabalhado como proposta em disciplinas relacionadas ao ensino técnico.

O estudo ainda considera a aquaponia como um sistema de cultivo de alimentos com uso racional do recurso hídrico, que integra a aquicultura e a hidroponia em sistemas de recirculação de água e nutrientes. Considerando que a aquaponia pode ser considerada uma alternativa sustentável atenuante dos impactos ambientais dos sistemas convencionais de produção aquícola e pode ser vista como uma 89 alternativa econômica e sustentável para o cultivo de alimentos sem utilização de produtos químicos no sistema. É de grande relevância trabalhos relacionados a esta prática como medida mitigadora dos impactos gerados ao ambiente.

$\mathrm{Na}$ mesma categoria o estudo (A) identificou como prática de sustentabilidade a visita em baixo contingente, às áreas naturais da reserva estudada, limitando desta forma a exploração de seus potenciais turísticos e levando a promoção das noções de sustentabilidade ambiental e cultural, contribuindo para a conservação/preservação das áreas exploradas. Enquanto que o estudo (C) constatou como ações de sustentabilidade (que se relacionavam com a temática do estudo) projetos de extensão de uma biblioteca no município de Imbituba - SC, realizado na praia como estratégia para atrair potenciais usuários, entre esses projetos se encontra o lançamento de livros para os usuários potencias, com temática de preservação ambiental, eventos da baleia franca com publicação de 
livros sobre educação ambiental e sobre preservação de espécies. Porém o autor ainda salienta que existe a necessidade de realizações de atividades mais voltadas para a promoção e circulação de matérias relacionados à orientação sobre a gestão da água e pesca.

Para o estudo (F) contemplado na mesma categoria, a contribuição acerca das práticas e ações sustentáveis ocorreu em torno da discussão do potencial da educação para promoção dessas ações. O estudo aponta a educação como responsável pelo olhar de complexidade a problemática ambiental, sendo esta capaz de agregar informações, de incluir os educandos em debates relacionados à problemática ambiental, ou em ações cotidianas. Foi visto como apontamento para promoção da sustentabilidade no setor pesqueiro, o fato do estudo sugerir como alternativas a promoção de práticas relacionadas a manter a qualidade das águas, redução de produção de resíduos e ações de cobrança das autoridades para implementação de aspectos legais e aplicações de leis ambientais existentes.

Para a segunda categoria Gestão de recursos naturais identificou-se como ações de sustentabilidade no estudo (G) os métodos tradicionais de manejo dos recursos pesqueiros, sendo descritas práticas de manejo delineadas por Folke et al. (1998), tais como: monitoramento de mudanças ecossistêmicas e de abundância de recursos; proteção integral de espécies específicas; proteção de espécies de acordo com seus estágios vulneráveis; proteção de habitats específicos; restrições em tempos determinados para capturas de espécies; manejo integrado de múltiplas espécies; rotatividade de recursos; entre outros.

O estudo $(H)$ contribuiu na disseminação de informações acerca da aquicultura orgânica na Europa que é apontada como ator principal para as práticas de sustentabilidade no setor aquícola onde as entradas de recursos são reduzidas ao mínimo, comparadas as saídas de produtos e resíduos; e aplicados a sistemas extensivos e semi-íntensivos, que se harmonizam integrados a paisagem circundante. $\mathrm{O}$ estudo (I) sugeriu um plano de manejo bem elaborado com boas práticas de sustentabilidade no que se refere à introdução de espécies de peixes exóticas concentrando informações através de um programa de educação específica para a comunidade da região estudada e enfatiza que para serem eficiente essas práticas precisam estarem fundamentadas no aumento da participação comunitária e no incentivo das instituições locais, facilitando o processo de participação e formulação de políticas, para o estabelecimento de estratégias e bem sucedidas medidas de conservação e de tomada de decisões que não afetem o ecossistema da região.

Para o estudo ( $\mathrm{J}$ ) foi apenas sugerido a necessidade de práticas de gerenciamento adequado para aumento dos esforços de conservação marinha da região estudada. Foi identificado no estudo que a 90 região é amparada por um programa de gerenciamento projetado para a promoção de ações sustentáveis voltadas para a conservação da biodiversidade da região, mas estas ações não foram relatadas. No que diz respeito às práticas conservacionistas, o estudo $(\mathrm{M})$ enfatizou que é necessário estudos adicionais que tratem da exploração dos recursos pesqueiros para que práticas de manejo sustentável e ações conservacionistas sejam aplicadas adequadamente visando a manutenção da diversidade biológica. Sugerindo que no desenvolvimento e aplicação dessas práticas e ações, possam ser levado em conta os conhecimentos tradicionais os pescadores artesanais, servindo desta forma como fonte informacional no que se refere ao status atual dos recursos, de sua dinâmica ecossistêmica e de suas características ambientais locais.

Para a terceira categoria Indústria e práticas sustentáveis o estudo (D) também esteve relacionado a sistemas aquapônicos, porém o estudo foi realizado 
fora do Brasil. Já no estudo (E) foram identificadas ações sustentáveis relacionadas a medidas de gestão de recursos naturais que possam trazer resoluções ou mitigações aos problemas de impacto ambiental causado pelo setor aquícola. São apontadas como práticas de sustentabilidade ambiental o cultivo integrado, a exemplo da policultura de bivalves, peixes e camarões, onde os resíduos gerados podem ser recirculados dentro das fazendas, evitando desta forma a o empobrecimento ou sobrecarga do ambiente. Porém a prática se limita caracteristicamente a sistemas com tanques de áreas maiores.

Outra prática apontada é a implementação em sistemas hiper-intensivos, de mecanismos zero de descarga, desse modo não liberando efluentes para o ambiente, este seria o tipo de sistema que abarca o tratamento e a recirculação dos resíduos do viveiro, com esterilização dos tanques com antibiótico e outras substancias. Porém o estudo informa que estas ações mitigadoras com grande rigor na produção, estão limitadas a um elevado investimento de capital.

O estudo aponta outra prática para promoção da sustentabilidade que está relacionada com a biotecnologia, a denominada tecnologia de Bio-flocos. Sendo esta, uma técnica de controle de impactos ambientais que vem ganhando espaço no setor. Segundo o estudo a técnica se caracteriza pela utilização de altas densidades de cultivo, e promove aumento da produtividade, mesmo em pouca ou nenhuma troca de água, o que corrobora consideravelmente para a diminuição de emissões de efluentes para o meio ambiente.

Por fim, o estudo (L) contribuiu sugerindo com boas práticas de gestão pautada na sustentabilidade, no qual foram delineadas práticas de monitoramento regular da qualidade da água e quantidade, avaliação do estoque de peixes, prevenção do processo de eutrofização, sedimentação e outros fatores que possam alterar fisicamente, quimicamente ou biologicamente a qualidade da água, aplicações da regulamentação de pesca, adoção de melhores práticas de manejo para o reservatório estudado entre outras sugestões.

Para esta levantamento identificou-se que a maioria das práticas ambientais implementadas ou ações sugeridas se relacionou com pesquisas científicas ligadas à indústria, instituições, ou aspectos etnológicos. Assim sendo poucos estudos estiveram relacionados com à área educacional disciplinar. Porém todos os estudos deram sua contribuição no quesito sustentabilidade, ressaltando sua importância para o desenvolvimento das atividades estudadas. Para tanto $33 \%$ dos estudos se relacionaram com práticas de sustentabilidade através de suas ações e evidenciaram a importância dessas ações para a conservação do ambiente. Deste modo o estudo (A) indicou que há um conjunto de importantes iniciativas por parte dos professores da Reserva de Desenvolvimento 91 Sustentável Estadual Ponta do Tubarão, no fomento à construção de conhecimentos relacionados à Educação Ambiental, contribuindo assim, direta e indiretamente para a conservação dos recursos naturais da Reserva.

$\mathrm{O}$ estudo (B) mostrou que as avaliações finais dos professores que utilizaram o sistema aquapônico como atividade prática foram bem positivas. $\mathrm{O}$ estudo (C) observou a inserção de algumas atividades culturais envolvendo a sustentabilidade. O estudo também revelou que o desenvolvimento sustentável carece de um ambiente propício à sua aprendizagem e ao trabalho colaborativo e depende de um estabelecimento de parcerias entre governo, comunidade e instituições locais. O estudo (I) avaliou o conhecimento local como uma importante ferramenta para a conservação ecológica, principalmente devida sua contribuição para a gestão local. Constatou-se ainda que a população local tem um conhecimento bem estabelecido de como as 
relações ecológicas ocorrem dentro de suas práticas de uso dos recursos.

O levantamento também indicou que $17 \%$ dos estudos se utilizaram de métodos de manejo e conservação para sustentabilidade do ambiente. Sendo que para o estudo (D) relacionado ao sistema aquapônico, foi avaliado que a qualidade de água poderia ser mantida dentro de faixas apropriadas para a produção de peixes e plantas. A hortelã foi definida como a planta com maior produtividade observada, sugerindo que esta planta assimila os nutrientes produzidos nesse tipo de sistema mais eficientemente. Já o estudo $(G)$ constatou sete práticas de manejo baseadas no conhecimento local ecológico e quatro mecanismos sociais que se relacionam com as práticas, também se constatou três inovações pesqueiras que estão relacionadas à transferência geográfica de conhecimento.

A maioria dos estudos se basearam em sugestões de ações ou métodos de manejo e conservação, para um caminho sustentável, um total de $50 \%$ dos estudos. Para isto o estudo (E) sugeriu que é possível tornar a carcinicultura rentável e sustentável ao mesmo tempo, por meio da implementação de medidas mitigadoras e de aplicação das leis e diretrizes existentes no setor. $\mathrm{O}$ estudo (F) evidenciou a necessidade de um suporte instrumental para que a educação ambiental e a problematização da crise ambiental possam progredir. Destacou que não se torna possível isso acontecer sem a capacitação dos educadores, sem os materiais didáticos congruentes e adaptados ao contexto da localidade. Já o estudo (H) sugeriu que a crise global atual se relaciona diretamente com o clima, o ambiente físico, a biodiversidade, a economia o e bem-estar social; bem como sugeriu que a aplicação de princípios radicais de decrescimento econômicos sustentável, como forma de proteger os recursos naturais, e reduzir a desigualdade social, pode ser admitida como um processo de ação e remediação dirigida pela sociedade e como ferramenta sólida para reverter as consequências ecológicas produzidas pelo capitalismo. O estudo (J) indicou que a conservação da reserva estudada careceu de estratégias que contribuam para o manejo e conservação do ecossistema. Também sugeriu que tais estratégias possam considerar os pontos de vista dos pescadores para os processos de negociação e legislação.

O estudo (L) evidenciou que a estimativa para o reservatório estudado foi maior que os outros reservatórios e que o alto conteúdo iônico do reservatório, altos níveis de nutrientes e oxigênio dissolvido, bom $\mathrm{pH}$, o baixo nível de poluição e profundidade superficial do reservatório foram responsáveis pela alta estimativa de produção de peixes. O estudo sugeriu que para a sustentabilidade das pescarias, deve ser adotada uma gestão eficaz do reservatório para coibir a eutrofização e serem 92 implementadas práticas de manejo e implementação da regulamentação de pesca. Já o estudo (M) constatou que a presença de espécies que representam recursosalvo deve ser levada em consideração no que diz respeito à elaboração de práticas de manejo e conservação. A biodiversidade dos recursos explorados registrada no estudo evidenciou a importância dos manguezais para comunidades que se desenvolvem em seu entorno e sugeriu que os dados obtidos podem servir de base para a elaboração de projetos de manejo que visem à conservação dos recursos e da diversidade cultural.

\section{Educação como foco para disseminação das práticas de sustentabilidade ambiental}

A educação formal e informal para a construção de cidadãos ativos e conscientes tem um grande potencial para produção e formação de resultados de médio e longo prazo. Portanto a educação não tem responsabilidade direta sobre os problemas sociais, 
porém se responsabiliza indiretamente sobre a formação consciente dos indivíduos e de capacitação de atribuições significativas quanto às relações sociais, as relações homem-ambiente e o modo de agir segundo a construção dos sentidos, assumindo desta forma a educação e seus educadores, diversas concepções e práticas educativas (COSTA; GUSTAVO; LAYRARGUES, 2014).

Dentro do contexto ambiental, a proposição de uma educação baseada na práxis, traz a conjectura do desenvolvimento funcional da compreensão teóricocrítica acerca dos problemas o que eleva o indivíduo ao papel de construtor de realidades por meio das práticas transformadoras educacionais. Neste sentido Pereira (2008) enfatiza que a educação ambiental possui como uma de suas prioridades o dever de construir uma nova racionalidade no uso dos recursos naturais.

Para tanto a Agenda 21, referente à Conferência das Nações Unidas sobre Meio Ambiente e Desenvolvimento, a Educação Ambiental esta evidenciada no capítulo 36 intitulado "Promoção do Ensino, da Conscientização e do Treinamento", como um processo pelo qual as sociedades humanas podem desencadear o desenvolvimento pleno de suas potencialidades, através do ensino especialmente o ensino formal, da conscientização pública e do treinamento (2004). Sendo o ensino o agente fundamental para a promoção do desenvolvimento sustentável, é eficaz para gerar consciência ambiental, valores e atitudes, técnicas e comportamentos; favorecendo efetivamente a participação pública nas tomadas de decisão.

Quanto ao problema da educação fora das instituições de ensino, o estudo de Pereira (2008) coloca em discussão a problemática da educação formal e informal para as comunidades pesqueiras, sendo estas alcançadas pela educação informal através de projetos sociais, programas e pesquisas direcionadas a estas comunidades e no que se refere à educação formal esta é bastante defasada se levarmos em conta os problemas cotidianos destas localidades que muitas vezes não se relacionam com o conhecimento apreendido. Para isso a educação ambiental voltada para as comunidades pesqueiras através de projetos e ações, deve estar pautada em práticas socioambientais que envolvam as expressões do grupo, corroborando desta forma com as soluções de problemas sociais e ambientais destas comunidades.

\section{CONCLUSÃO}

Depreende-se que são muitos os estudos que abordam a temática da sustentabilidade, discutindo e sugerindo a implantação de boas práticas de gestão, manejo e sustentabilidade e que poucos trabalhos que tratam da sustentabilidade, delineiam as práticas sustentáveis/ambientais necessárias para o caminho 93 dessa sustentabilidade. Os estudos acerca das práticas de sustentabilidade direcionadas ao setor pesqueiro ainda são bastante tímidos, com produção muito exígua, quando comparada com a mesma temática para outras áreas.

As iniciativas relacionadas à sustentabilidade ambiental abordadas nos trabalhos analisados, são muito relevantes para o setor pesqueiro, tendo em vista que o setor enfrenta grandes dificuldades relacionadas a sobre-exploração insustentável dos recursos pesqueiros, a extinção de espécies em consequência dessa sobre-exploração e a carência de medidas de gestão, refletindo desta forma na escassez da biodiversidade marinha. Quanto às medidas de gestão, se faz necessário que a gestão pesqueira seja construída com base em conhecimento cientifico e tecnológico, dessa forma é necessário o incentivo de pesquisas sobre a área com fim de melhorias das informações o que pode contribuir significativamente nas tomadas de decisões políticas no que diz respeito 
à garantia da sustentabilidade pesqueira e ambiental e na proteção da biodiversidade aquática e dos recursos hídricos.

Porém para isso existe a necessidade de organização e delineamento desse conhecimento em um contexto que estas informações sejam apropriadas e enquadradas nas questões de desenvolvimento sustentável, econômico, nas melhorias educacionais e na práxis dentre outros contextos de modo que haja um bom subsidiamento na gestão dos recursos pesqueiros (RODRIGUES, 2015).

Desta forma, as melhorias de informações de conhecimento cientifico e tecnológico para o setor, permitem aos pesquisadores e profissionais das áreas afins uma melhor compreensão dos benefícios que as práticas de sustentabilidade pode trazer quando aplicadas ao setor, estimulando estudos e pesquisas futuras relacionadas a temática pesquisada.

Todos os autores declararam não haver qualquer potencial conflito de interesses referente a este artigo.

\section{REFERÊNCIAS}

BOFF, L. Sustentabilidade: o que é - O que não é. Petrópolis: Vozes, 2017.

CHANTHAMALEE, J.; WONGCHITPHIMON, T.; LUEPROMCHAI, E. Treatment of Oily Bilge Water from Small Fishing Vessels by PUF-Immobilized Gordonia sp. JC11. Water, Air \& Soil Pollution. v. 224 , n.7, p. 1, 2013. DOI: 10.1007/s11270-0131601-6.

COMISSÃO MUNDIAL SOBRE MEIO AMBIENTE E DESENVOLVIMENTO (CMMAD). Nosso futuro comum. Rio de Janeiro: Fundação Getúlio Vargas, 1988.

FAO. The State of World Fisheries and Aquaculture - Meeting the sustainable development goals. v. 367, Roma, 2018.

FARIAS, D. S. D. de; ALENCAR, A. E. B. de; BOMFIM, A. da C.; FRAGOSO, A. B. de L.; ROSSI, S.; MOURA, G. J. B de; GAVILAN, S. A.; SILVA, F. J. de L. Marine Turtles Stranded in Northeastern Brazil: Composition, Spatio-Temporal Distribution, and Anthropogenic Interactions. Chelonian
Conservation and Biology, v.18, n.1, p.105-111, 2019. DOI: $10.2744 / C C B-1309.1$.

GOMES R. N.; JORDÃO FILHO, J.; MENDES, G. O. Análise técnica da produção de Tilápias no município de Bananeiras-PB. Caderno Verde de Agroecologia e Desenvolvimento Sustentável. Pombal, v.2, n.1, p. 1- 4, 2012.

GRANZIERA, M. L. M.; GONÇALVES, A. Os problemas da zona costeira no Brasil e no mundo. São Paulo: Universitária Leopoldianum, 2012.

GUIMARÃES, M. Educação Ambiental Crítica. In: LAYRARGUES, Phillipe Pomier (coord.). Identidades da Educação Ambiental Brasileira. Brasília: Ministério do Meio Ambiente, 2004. p. 2534.

JACOBI, P. R. Meio ambiente urbano e sustentabilidade: alguns elementos para a reflexão. In: CAVALCANTI, C. (Org.). Meio ambiente, desenvolvimento sustentável e políticas públicas. São Paulo: Cortez Editora, 1997. p. 384-390.

Movimento ambientalista no Brasil: Representação social e complexidade da articulação de práticas coletivas. In: RIBEIRO, W. C. (Org.). 94 Patrimônio Ambiental Brasileiro. São Paulo: EDUSP, 2003. p. 519-543.

LIMA, G. F. da C.; LAYRARGUES, P. P. Mudanças climáticas, educação e meio ambiente: para além do Conservadorismo Dinâmico. Educar em Revista, v.30, n. 3, p. 73-88, 2014. DOI: 10.1590/01044060.38108.

MACFADYEN, G.; HUNTINGTON, T.; CAPPELL, R. Abandoned, lost or otherwise discarded fishing gear. Roma: Food and Agriculture Organization of the United Nations (FAO), 2009.

MATHIESEN, A. El estado mundial de la pesca y la acuicultura. Roma: Departamento de Pesca y Acuicultura de la Organización de las Naciones Unidas para la Alimentación y la Agricultura (FAO), 2012.

MEADOWS, D. H.; MEADOWS, D. N.; RANDERS, J. Limites do crescimento: um relatório para o Projeto do Clube de Roma sobre o dilema da humanidade. Tradução: Inês Maria Fonseca Litto. São Paulo: Perspectiva, 1973.

MELO, A. S. S. A.; BARROS, A. D. de. Pesca predatória da lagosta no Brasil: um modelo insustentável. In: CONGRESSO DA SOCIEDADE BRASILEIRA DE ECONOMIA E SOCIOLOGIA RURAL. 44. Anais. Fortaleza: SOBER, 2006. 
MOORE, M. L.; PORTEN, S. V. D.; PLUMMER, R.; BRANDES, O.; BAIRD, J. Water policy reform and innovation: A systematic review. Environ. Sci. Policy, v. 38, p. 263-271, 2014. DOI:10.1016/j.envsci.2014.01.007.

NASCIMENTO, G. C. C. do; CÓRDULA, E. B. de L; BENÍCIO, D. A.; OLIVEIRA, P. A. de; SILVA, M. C. B. C. da. Recursos Pesqueiros no Brasil: Apropriação Tecnológica para o desenvolvimento sustentável. Revista Eletrônica em Gestão, Educação e Tecnologia Ambiental, Santa Maria. v. 19, n. 3, p. 735-743, 2015. DOI: $10.5902 / 2236117018122$.

ONU. Declaração da Conferência das Nações Unidas sobre o Meio Ambiente Humano - 1972. Conferência das Nações Unidas sobre o Meio Ambiente Humano. Estocolmo, 1972, 13p.

PEREIRA, M. O. da R. Educação ambiental com pescadores artesanais: um convite à participação. Práxis Educativa, v. 3, n. 1, p. 73-80, 2008. DOI: 10.5212/PraxEduc.v.3i1073080.

PITTMAN, J., ARMITAGE, D. Governance across the land-sea interface: A systematic review. Environ. Sci. Policy, v. 64, p. 9-17, 2016. DOI:10.1016/j.envsci.2016.05.022.

PLUMMER, R.; CRONA, B.; ARMITAGE D. R.; OLSSON, P.; TENGÖ M.; YUDINA O. Adaptive comanagement: a systematic review and analysis. Ecology and Society, v. 17, n. 3, 2012. DOI:10.5751/ES-04952- 170311.

REBOUÇAS, G. N. M.; FILARDI, A. C. L.; VIEIRA, P. F. Gestão integrada e participativa da pesca artesanal: potencialidades e obstáculos no litoral do estado de Santa Catarina. Ambiente \& Sociedade, São Paulo. v. 9, n. 2, p. 83-104, 2006. DOI: 10.1590/S1414-753X2006000200005.
RODRIGUES, C. A contribuição da gestão da informação para o uso dos recursos pesqueiros no Brasil. Revista CEPSUL- Biodiversidade e Conservação Marinha, v. 4, n. 1, p. 16-28, 2015.

SENADO FEDERAL. Agenda 21 - Conferência das Nações Unidas sobre Meio Ambiente e Desenvolvimento. 3.ed. Brasília: Senado Federal, Subsecretaria de Edições, 2001.598 p.

SEVERO, E. A.; DE GUIMARÃES, J. C. F. Trajetórias e perspectivas da sustentabilidade e práticas ambientais: uma pesquisa bibliométrica. Revista Metropolitana de Sustentabilidade, São Paulo. v. 7, n. 2, p. 93-114, 2017.

SIQUEIRA, T. V. Aquicultura: a nova fronteira para aumentar a produção mundial de alimentos de forma sustentável. Boletim Regional, Urbano e Ambiental, Rio de Janeiro, n 17, p. 53-60, Jul./Dez. 2017.

SMITH, A. D. M.; BROWN, J. C.; BULMAN, C. M.; FULTON, E. A.; JOHNSON P.; KAPLAN, I. C.; LOZANO-MONTES, H.; MACKINSON, S.; MARZLOFF, M.; SHANNON, L. J., SHIN, Y-J; TAM, J. Impacts of fishing low - Trophic Level Species on Marine Ecosystems. Science, v. 333, n. 6046, p. 1147-1150, 2011. DOI: 95 10.1126/science. 1209395 .

SOUZA, R. T. Y. B. de. SOUZA, L. de O. OLIVEIRA, S. R. de. TAKAHASHI, E. L. H. Formação continuada de professores de ciências utilizando a Aquaponia como ferramenta didática. Ciência \& Educação (Bauru), v. 25, n. 2, p. 395-410, 2019.

UNESCO. Carta de Belgrado. Uma estrutura global para a educação ambiental. Encontro Internacional em Educação Ambiental. Belgrado, 1975, 4p. 